\title{
Aerosol optical depth retrievals at the Izaña Atmospheric Observatory from 1941 to 2013 by using artificial neural networks
}

\author{
R. D. García ${ }^{1,2}$, O. E. García ${ }^{1}$, E. Cuevas ${ }^{1}$, V. E. Cachorro ${ }^{2}$, A. Barreto ${ }^{1,3}$, C. Guirado-Fuentes ${ }^{1,2}$, N. Kouremeti ${ }^{4}$, \\ J. J. Bustos ${ }^{1}$, P. M. Romero-Campos ${ }^{1}$, and A. M. de Frutos ${ }^{2}$ \\ ${ }^{1}$ Izaña Atmospheric Research Center (IARC), Agencia Estatal de Meteorología (AEMET), Santa Cruz de Tenerife, Spain \\ ${ }^{2}$ Atmospheric Optics Group, Valladolid University, Valladolid, Spain \\ ${ }^{3}$ Cimel Electronique, Paris, France \\ ${ }^{4}$ Physikalish-Meteorologisches Observatorium, Davos, World Radiation Center, Davos, Switzerland
}

Correspondence to: R. D. García (rgarciac@aemet.es)

Received: 23 July 2015 - Published in Atmos. Meas. Tech. Discuss.: 3 September 2015

Revised: 18 December 2015 - Accepted: 21 December 2015 - Published: 15 January 2016

\begin{abstract}
This paper presents the reconstruction of a 73-year time series of the aerosol optical depth (AOD) at $500 \mathrm{~nm}$ at the subtropical high-mountain Izaña Atmospheric Observatory (IZO) located in Tenerife (Canary Islands, Spain). For this purpose, we have combined AOD estimates from artificial neural networks (ANNs) from 1941 to 2001 and AOD measurements directly obtained with a Precision Filter Radiometer (PFR) between 2003 and 2013. The analysis is limited to summer months (July-August-September), when the largest aerosol load is observed at IZO (Saharan mineral dust particles). The ANN AOD time series has been comprehensively validated against coincident AOD measurements performed with a solar spectrometer Mark-I (1984-2009) and AERONET (AErosol RObotic NETwork) CIMEL photometers (2004-2009) at IZO, obtaining a rather good agreement on a daily basis: Pearson coefficient, $R$, of 0.97 between AERONET and ANN AOD, and 0.93 between Mark-I and ANN AOD estimates. In addition, we have analysed the long-term consistency between ANN AOD time series and long-term meteorological records identifying Saharan mineral dust events at IZO (synoptical observations and local wind records). Both analyses provide consistent results, with correlations $>85 \%$. Therefore, we can conclude that the reconstructed AOD time series captures well the AOD variations and dust-laden Saharan air mass outbreaks on shortterm and long-term timescales and, thus, it is suitable to be used in climate analysis.
\end{abstract}

\section{Introduction}

Solar radiation reaching the Earth's surface (SSR) plays a key role in our climate and environment. In the last decades, numerous analyses have demonstrated that SSR records have not been constant over time, but have undergone climatologically significant decadal variations (e.g. Pallé and Butler, 2001; Stanhill and Cohen, 2001; Sanchez-Lorenzo et al., 2007; Wild, 2009; García et al., 2014a). From the 1930s to the early 1950s the few data available suggest an increase of the SSR in the first part of the 20th century, known as early brightening. This period is followed by a widespread period of reduced solar radiation from the 1950s to the end of the 1990s. This effect, extensively reported by the literature at a global scale, is known as dimming, with a general decline between 4 and $6 \%$ decade $^{-1}$ considering worldwide distributed stations. Recently, a gradual increase of the SSR has been documented, known as brightening, with trends between +1 and $+11 \%$ decade $^{-1}$ from the 1980 s onwards (Ohmura and Lang, 1989; De Bruin et al., 1995; Gilgen et al., 1998; Stanhill and Cohen, 2001; Ohmura, 2006; Wild et al., 2005; Sanchez-Lorenzo et al., 2007; Wild et al., 2008; Wild, 2009; Lachat and Wehrli , 2013; García et al., 2014a).

The causes of these phenomena are not fully understood currently, but it has been pointed out that changes in the transmissivity of the Earth's atmosphere play a significant role. These changes might be due to changes on global cloud cover and atmospheric aerosol concentrations. Wild et al. (2005) found that the changes are observed under all cloud- 
cover conditions, thus probably the most important cause is the aerosol effects (Kaufman et al., 2002). In this context, the study of the spatial and temporal variability of atmospheric aerosols at sites in background conditions can offer crucial insights to account for their key role on the observed SSR trends. For this purpose, reliable long-term series of aerosol content and properties are fundamental. However, these long-term series are only available typically since the middle of the 1970s, due to the poor data quality and changes in measurements methodology before this date. There are few studies treating aerosol long-term series in the literature. The longest available series are those of normal direct irradiance measured at various stations in Russia, Ukraine and Estonia covering together a 102-year period (1906-2007) with which the atmospheric transparency has been estimated (Ohvril et al., 2009). Kudo et al. (2011) estimated aerosol optical depth (AOD) combining broadband direct and diffuse irradiance measurements performed at Tsukuba, Japan, from 1975 to 2008. Shaw (1979) and Holben et al. (2001) studied long-term series of AOD from sun photometry at Mauna Loa since 1976, and Barreto et al. (2014) derived AOD from solar irradiance measurements at Izaña Atmospheric Observatory (IZO) since 1976. All of these studies are based on solar spectrometry, but a different approach is needed to obtain longer AOD time series.

One of the most powerful tools used in science in the last decades are the artificial neural networks (ANNs). The ANNs have been employed in diverse applications and fields such as robotics, pattern recognition, forecasting, medicine, power systems, etc. In atmospheric science the use of ANNs is quite recent, for example, ANNs have been successfully used for estimating solar radiation values (Mohandes et al., 1998; Dorvlo et al., 2002; López et al., 2005; Feister and Junk, 2006; Junk et al., 2007; Feister et al., 2008; Paoli et al., 2009; Linares-Rodríguez et al., 2011, 2013) or cloud properties (González et al., 2002; Cerdeña et al., 2006). However, their use for AOD estimations is quite recent and limited to short periods. For example, Cazorla et al. (2008) estimated AOD values from all-sky images at Granada (Spain) between 2005 and 2006, finding uncertainties of 0.019 and 0.014 for AOD at 440 and $670 \mathrm{~nm}$, respectively, by comparing with AERONET (AErosol RObotic NETwork; http://aeronet. gsfc.nasa.gov) AOD observations. Also, Foyo-Moreno et al. (2014) used ANNs to obtained AOD from global, diffuse and direct normal irradiance in Granada between 2006 and 2008. They found uncertainties of $\sim 13 \%$ with respect to AERONET AOD values.

In this context, the goal of this paper is to estimate the long-term AOD time series of Saharan mineral dust events at IZO and to document its quality and long-term consistency by a comprehensive validation study. This has been done by using ANN techniques and, as input parameters, in situ meteorological observations performed at IZO between 1941 and 2001. The estimated ANN AOD time series has been completed with AOD observations from sun photometry since

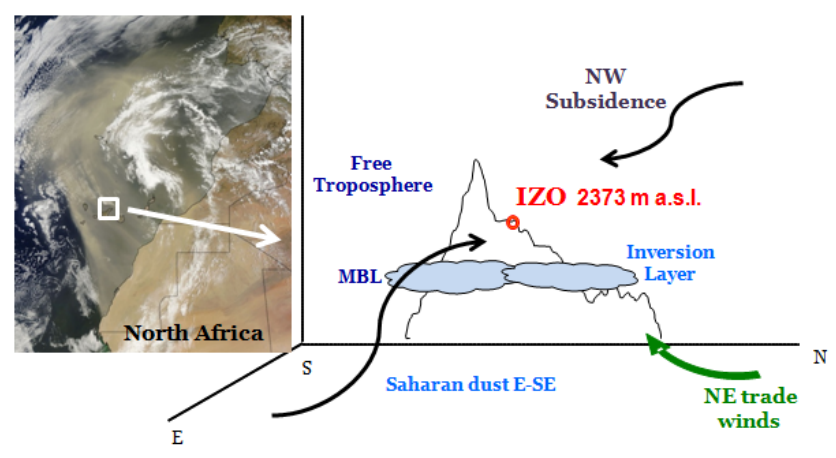

Figure 1. (a) MODIS/Terra image showing a strong Saharan dust outbreak over the study area (the Canary Islands) on 25 June 2012; (b) vertical cross section of Tenerife with a scheme of the vertical atmospheric stratification (marine boundary layer (MBL), inversion layer, and free troposphere) and the main atmospheric flows affecting IZO (NW clean subtropical subsident air masses, low-level NE trade winds, and E-SE Saharan dust intrusions). This figure has been adapted from González et al. (2014).

2003. Given the strategic location of IZO, very close to the Saharan desert, the reconstructed ANN AOD time series provide interesting clues on the intensity and the interannual and interdecadal variability of Saharan dust outbreaks over the North Atlantic. This might have important implications for climate analysis. To address this study, this paper has been divided as follows. Section 2 describes the main characteristics of the site where the ANN AOD estimates have been obtained, while Sect. 3 presents the architecture, training process and input parameters used to select the optimal ANN configuration, as well as an error analysis of ANN AOD estimations. Section 4 shows the validation of ANN AOD estimates with coincident AOD measurements, whereas the comparison between long-term ANN AOD and meteorological records is addressed in Sect. 5. Finally, a summary and the main conclusions are given in Sect. 6.

\section{Description of site and aerosol conditions}

Izaña Atmospheric Observatory (http://izana.aemet.es) is a high-mountain observatory located in Tenerife (Canary Islands) at $28.3^{\circ} \mathrm{N}, 16.5^{\circ} \mathrm{W}, 2373 \mathrm{ma}$ a.s.l., and situated approximately $300 \mathrm{~km}$ west from the African coast (Fig. 1a). IZO is managed by the Izaña Atmospheric Research Center (IARC) which forms part of the Meteorological State Agency of Spain (AEMET).

The observatory is located above a strong subtropical temperature inversion layer, which acts as a natural barrier for local pollution (Fig. 1b). In addition, IZO is affected by a quasi-permanent subsidence regime typical of subtropical latitudes, therefore the air surrounding the observatory is representative of the background free troposphere (especially at night-time). The combination of these two features makes IZO excellent for in situ and remote sensing atmo- 
spheric measurements and those features highlight the historical importance of the site. The first meteorological observations date from 1916 (DGIGE, 1915). In 1984 IZO became a World Meteorological Organization (WMO) Background Atmospheric Pollution Monitoring Network (BAPMon), and afterwards (1989), a Global Atmosphere Watch (GAW) station. IZO has been part of NDACC (Network for the Detection of Atmospheric Composition Change) since 2001, and has actively contributed to international aerosols and radiation networks such as GAW/PFR (Precision Filter Radiometer Network) since 2001, AERONET (Aerosol Robotic Network) since 2004 and BSRN (Baseline Surface Radiation Network) since 2009. In 2014, IZO was appointed by WMO as a CIMO (Commission for Instruments and Methods of Observation) Testbed for Aerosols and Water Vapour Remote Sensing Instruments (Cuevas et al., 2015a).

The typical background free troposphere conditions at IZO are only significantly modified in summer, mainly in July and August, when the most intense and relatively frequent Saharan air mass outbreaks in the subtropical free troposphere reach the observatory (Cuevas, 1996; Rodríguez et al., 2011; Cuevas et al., 2013, 2015b; Barreto et al., 2014; Rodríguez et al., 2015). During these months, Saharan dust long-range transport over the Atlantic that can reach the Caribbean is driven by incursions of the so-called Saharan air layer (SAL) over the North Atlantic (Prospero et al., 2002, and references therein).

In order to discriminate these two atmospheric conditions at IZO (clean free troposphere and presence of the SAL) we have combined AOD and Ångström exponent $(\alpha)$ information. While AOD provides the overall solar extinction effect of aerosols, $\alpha$ characterizes the AOD spectral variation, which is related to the aerosol median size (Kaufman et al., 1994). High $\alpha$ values indicate fine particle predominance, while low $\alpha$ values are related to coarse particles (Kaufman et al., 1994; Kim et al., 2011). Figure 2 illustrates an example of AOD- $\alpha$ distributions, showing the daily AOD time series at $500 \mathrm{~nm}$ labelled with the corresponding daily $\alpha$ values since AERONET records are available at IZO (2004 onwards). Values of AOD $\leq 0.10$ and $\alpha \geq 0.75$ (zone I, $63 \%$ of days), correspond to background conditions, while values of AOD $\geq 0.20$ and $\leq 0.50$ (zone II, $9 \%$ of days), are associated with Saharan dust episodes. Finally, the zone III, characterized by $0.10<\mathrm{AOD}<0.20$ and $0.50<\alpha<0.75(28 \%$ of days), describes the periods of transition between these two patterns. As observed, the Saharan dust events at IZO are mainly detected in summer months (July, August and September) with a median AOD value of $0.13 \pm 0.02$ and $\alpha$ of $0.47 \pm 0.03$, in contrast with the clean conditions observed in other months (median AOD and $\alpha$ of $0.05 \pm 0.01$ and $1.17 \pm 0.02$, respectively, for zone I and median AOD and $\alpha$ of $0.07 \pm 0.02$ and $0.67 \pm 0.03$, respectively, for zone III). Therefore, in this work, we have limited the ANN AOD estimation to summer months in order to assess the long-term variability of Saharan outbreaks over the subtropical Eastern

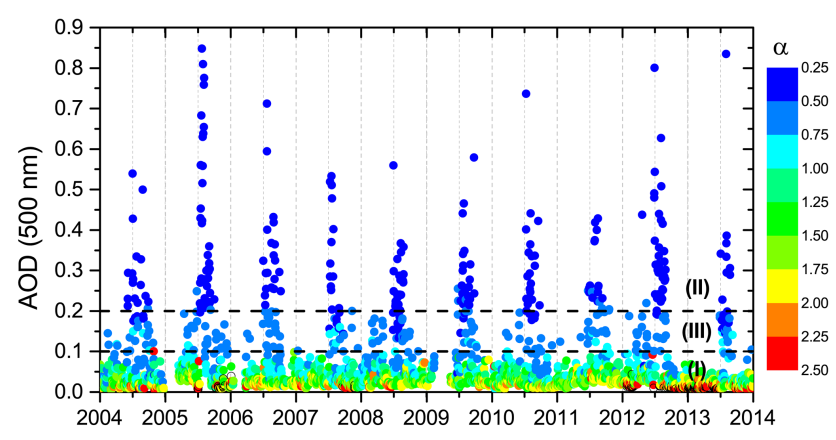

Figure 2. Daily AOD at $500 \mathrm{~nm}$ time series from AERONET between 2004 and 2013 at IZO. The colour scale indicates the daily Ånsgtröm exponent $(\alpha)$ values. The dashed lines distinguish the different AOD- $\alpha$ zones: (I) $\mathrm{AOD} \leq 0.10$ and $\alpha \geq 0.75$; (II) $\mathrm{AOD} \geq 0.20$ and $\alpha \leq 0.50$, and (III) $0.10<\mathrm{AOD}<0.20$ and $0.50<\alpha<0.75$.

North Atlantic. Note that, hereafter, we use AOD medians instead of means because the AOD values dramatically change by orders of magnitude from background conditions to dusty conditions. The errors are given as \pm 1 SEM (standard error of the median).

\section{Artificial neural networks (ANNs)}

ANN is a statistical data modelling tool, inspired by the human brain, capable of simulating highly nonlinear and complex relationships between inputs and outputs by a learning process, the so-called training process. This tool mainly consists of three layers of neurons: the input layer groups the input data in the input vector $\boldsymbol{p}$ and connects them with the hidden layer. In this layer the input vector is transformed into a net input vector, $\boldsymbol{a}^{\prime}$, by using adaptive weights, $\mathbf{W}^{h}$, biases, $\boldsymbol{b}^{h}$, and a transfer function, $\mathrm{TF}^{h}$, such as $\boldsymbol{a}^{\prime}=\mathrm{TF}^{h}(\boldsymbol{n})$, where $\boldsymbol{n}=\left(\mathbf{W}^{h} \boldsymbol{p}+\boldsymbol{b}^{h}\right)$. Then, the hidden layer is connected with the output layer, in which the outputs obtained in the previous step, $\boldsymbol{a}^{\prime}$, are transformed into the net input for the output layer, $n^{\prime}=\left(\boldsymbol{W}^{\text {out }} \boldsymbol{a}^{\prime}+b^{\text {out }}\right)$. Finally, the output transfer function, $\mathrm{TF}^{\text {out }}$, is applied to $n^{\prime}$ to obtain the final output of the ANN, $a$ (Jain et al., 1996, and references therein). The weights and biases used both in the hidden $\left(\mathbf{W}^{h}\right.$ and $\left.\boldsymbol{b}^{h}\right)$ and in the output layer ( $\boldsymbol{W}^{\text {out }}$ and $b^{\text {out }}$ ) were previously computed in the training process.

In this work, the ANNs have been implemented by using the Matlab Neural Network Toolbox (Demuth and Beale, 1993) with the architecture shown in Fig. 3: the input parameters of the input layer are different meteorological observations taken at IZO (Sect. 3.2 details the selection of these inputs), and the hidden layer is made up of 30 neurons with a transfer function defined by the hyperbolic tangent function:

$\varphi=\tanh (n)=\frac{e^{2 \mathrm{n}}-1}{e^{2 \mathrm{n}}+1}$, 


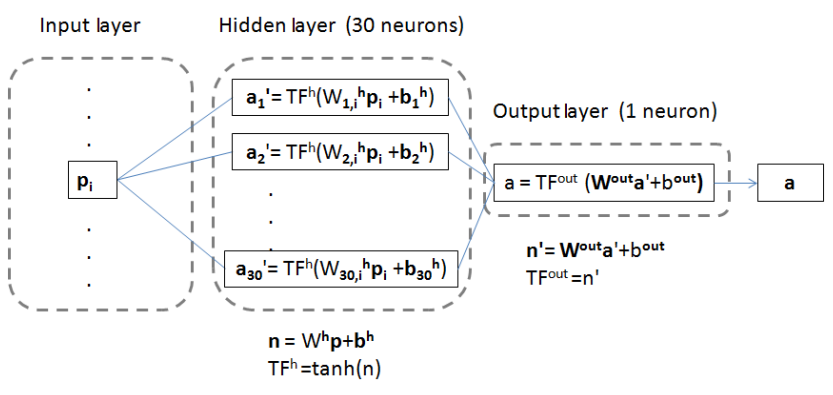

Figure 3. Schematic representation of the artificial neural network used in this study, where $p_{i}=p_{i}\left(N_{d i}, \mathrm{VIS}_{i}, \mathrm{FCS}_{i}, \mathrm{RH}_{i}, \mathrm{Temp}_{i}\right)$ with $i=1, \ldots, N$, with $N$ being the total number of observations and $a=$ ANN AOD.

where $\boldsymbol{n}$ is the corresponding net input. The hyperbolic tangent is one of the most used transfer function in ANN, since it successfully combines a fast learning rate with reliable results (Zhang et al., 1998; Ozkan and Erbek, 2013). Finally, the output layer has one neuron with the linear transfer function, which is often used in forecasting and approximation tasks (Zhang et al., 1998).

\subsection{Training process}

The learning or training procedure plays a key role in the ANN design and setting. In this process a set of inputs with known outputs (targets) are used to calculate the weights $\left(\mathbf{W}^{h}, \boldsymbol{W}^{\text {out }}\right)$ and biases $\left(\boldsymbol{b}^{h}, b^{\text {out }}\right)$ to be applied in the neural network, as explained in the previous section.

The first step on this process is to randomly divide the set of known inputs and target values into three different subsets: training ( $70 \%$ of the data), validation ( $15 \%$ of the data) and test (15\% of the data). The weights $\left(\mathbf{W}^{h}, \boldsymbol{W}^{\text {out }}\right)$ and biases $\left(\boldsymbol{b}^{h}, b^{\text {out }}\right)$ are computed for each neuron. Then the validation subset is used to estimate the error by comparing the obtained outputs with the targets of the validation subset. The computation of weights and biases and the subsequent error estimation is iteratively repeated until the error is lower than a required value or if the assignation of new weights and biases does not decrease the error. In this work the estimation of the error is supervised by the Levenberg-Marquardt optimization algorithm, which has proved to be efficient and fast for small and medium-sized networks, such as the architecture used here (Foresee and Hagan, 1997; Hao and Wilamowski, 2011). The mentioned error is computed by the mean square error (MSE) defined by the following equation:

$\mathrm{MSE}=\frac{1}{n} \sum_{i=1}^{N}\left(t_{i}-a_{i}\right)^{2}$,

where $N$ is the dimension of the validation subset, $t_{i}$ the targets in the validation subset and $a_{i}$ the ANN outputs obtained from the validation subset inputs. Finally, the test subset, not used in the training process, is used to check the quality of the obtained ANN by applying it to "clean" inputs, that is, inputs and targets not used in the training process (Beale et al., 2014).

Given that the division of known data in training, validation and test subsets is random, we have repeated the training process 1000 times. Then, the best ANN is selected as the one showing the highest Pearson correlation coefficient $(R)$, slope closest to 1 and lowest intercept with respect to the known outputs (Hao and Wilamowski, 2011).

The AOD measurements used to train the ANN were performed with one of the most accurate and stable instruments dedicated for atmospheric aerosol monitoring, a Precision Filter Radiometer (hereafter PFR AOD), developed at the World Radiation Center Physikalisch-Meteorologisches Observatorium (www.pmodwrc.ch). It was installed at IZO in the framework of a high-precision world network for AOD characterization and monitoring (GAW/PFR) in June 2001, but continuous observations are only available since 2003 . The PFR measures direct solar radiation, with a field of view of $2.5^{\circ}$, at $862,500,412$ and $368 \mathrm{~nm}$. The AOD is estimated at all these wavelengths with an expected uncertainty of \pm 0.01 (Wehrli, 2000). In this study, we have used Level 3.0 of Version $3.0 \mathrm{AOD}$ at $500 \mathrm{~nm}$.

\subsection{Input parameters and ANN AOD estimates}

The other critical step in the ANN design is the selection of an appropriate set of input parameters, since they should be able to adequately capture the actual variability of the target. A parameter describing the extinction of the solar radiation similarly to AOD is the horizontal visibility (VIS). The VIS is estimated by human observations (by observers) manually as the maximum distance at which the naked eye of an observer can distinguish a predetermined marker object (a building, a mountain, etc.) from the background (WMO, 1996). Therefore, it is very sensitive to the extinction of radiation by atmospheric aerosols - Retalis et al. (2010), and references therein - but also by the presence of hydrometeors (snow, fog, rain, ...) and clouds. To minimize the latter impacts on the variability of the VIS, we only work with cloud-free days filtered with an average sky cover of 0 oktas. Furthermore, we have introduced the fraction of clear sky (FCS) defined as the ratio between SD performed with a Campbell Stokes sunshine recorder (García et al., 2014a) and the maximum daily sunshine duration $\mathrm{SD}_{\max }$ to account for the remaining variability introduced by the presence of clouds, fog, etc. The introduction of FCS in the ANN training allows the ANN to discriminate the patterns associated with possible residual cloud cover for the days with oktas $=0$. The cloud-free days for the study were selected by considering a median number of oktas equal to zero, but this value was calculated from only three observations per day. Thereby, some episodes with cloud contamination are likely and, as pointed out by the referee, this residual cloud contamination could give artificial ANN AOD values. 


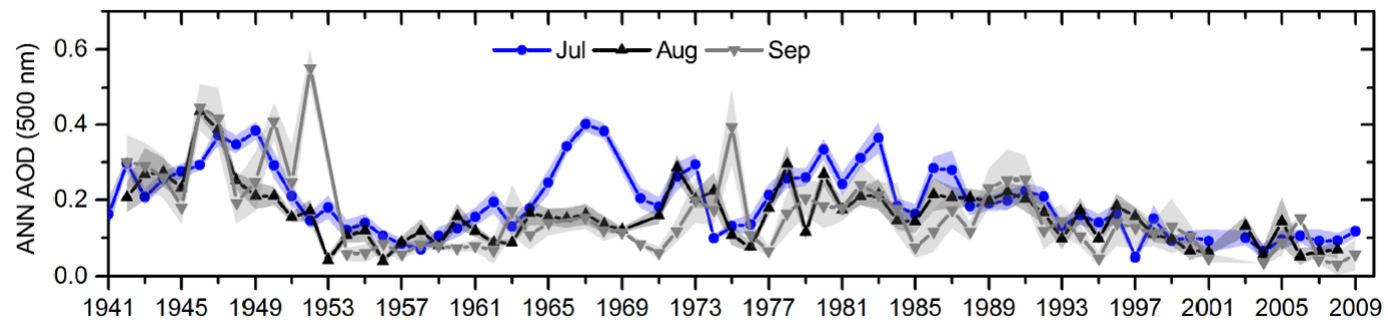

Figure 4. Times series of the ANN AOD monthly medians (July, August and September) at $500 \mathrm{~nm}$ between 1941 and 2009 at IZO. Shadings show the range of \pm 1 SEM (standard error of the monthly median).

Table 1. Parameters of the least-square fit (Pearson correlation coefficient, $R$, slope and intercept) between the measured PFR AOD and the estimated ANN AOD using different configurations of input parameters. The setup selected is highlighted in bold.

\begin{tabular}{lccr}
\hline Inputs & $R$ & Slope & Intercept \\
\hline (A) $N_{d}$-VIS & 0.79 & 0.61 & 0.03 \\
(B) $N_{d}$-VIS-FCS & 0.94 & 0.90 & 0.01 \\
(C) $\boldsymbol{N}_{\boldsymbol{d}}$-VIS-FCS-RH & $\mathbf{0 . 9 9}$ & $\mathbf{0 . 9 9}$ & $\mathbf{- 0 . 0 1}$ \\
(D) $N_{d}$-VIS-FCS-RH-Temp & 0.97 & 0.92 & 0.01 \\
\hline
\end{tabular}

To complete the characterization of the meteorological conditions, we have considered the relative humidity ( $\mathrm{RH})$ and temperature records $(T)$. The latter inputs are only available every $3 \mathrm{~h}$ between 06:00 and 18:00 UTC, thus we have calculated the daily medians. Finally, to account for the seasonal variation of each parameter we have also introduced the day of year $\left(N_{d}\right)$ as input parameter. The time series at IZO are from 1916 up to now for $T$ and RH, from 1921 to present for FCS, and from 1941 to 2009 for VIS. Therefore, the latter time series determines the period in which the ANN AOD time series can be estimated with ANN techniques: 19412009. These data were taken from the AEMET climatological database (http://www.aemet.es).

In order to study the relative importance of each input parameter and select the best configuration, several combinations of the input parameters has been trained, validated and tested in the period 2003-2009 (period with coincident PFR AOD and input parameter measurements). The different combinations considered were: (A) $N_{d}$ and VIS; (B) $N_{d}$, VIS and FCS; (C) $N_{d}$, VIS, FCS and RH; and (D) $N_{d}$, VIS, FCS, RH and Temp. As observed in Table 1, the VIS and FCS are the most critical parameters determining $\sim 90 \%$ of the observed AOD variance, although the maximum agreement is achieved when the RH is also taken into account as input parameter (setup C). This configuration accounts for $98 \%$ of the actual AOD variability with a slope of 0.99 and intercept of -0.01 between the measured and estimated AOD values. By applying this setup, we have obtained the daily ANN AOD time series between 1941 and 2009 at IZO, which is displayed in Fig. 4 on a monthly basis.
To analyse how the ANN AOD estimates could be affected by uncertainties in the input parameters used, we have performed a two-step theoretical error estimation. Firstly, AOD estimations were conducted using the measured values for all parameters described in the previous section, obtaining the non-perturbed values (AOD). Secondly, the same sample was simulated again by applying the typical uncertainties of the inputs parameters reported in the literature, $\pm 5 \%$ for FCS (García et al., 2014a) and $\pm 2 \%$ for RH (Thies, 2011). For the horizontal visibility we have assumed a very conservative error of $\pm 25 \%$. Note that the day of year has been omitted from this analysis.

This strategy was applied to all cloud-free days (oktas $=0$ ) between 2003 and 2009 in order to detect random and systematic behaviours in the error time series $(\mathrm{AOD} \pm \delta)(\mathrm{Gar}-$ cía et al., 2014b). As the theoretical error distributions have not shown dependence either on the input parameters or on the ANN AOD values (correlation is not significant at $95 \%$ level of confidence), the systematic and random errors have been calculated as the median and the standard deviation of the corresponding error distributions.

The results of our error analysis are summarized in Table 2, where the two prevalent atmospheric situations observed at IZO have been distinguished: free-troposphere background conditions with $\mathrm{AOD} \leq 0.10$ and $\alpha \geq 0.75$, and Saharan dust events with AOD $\geq 0.20$ and $\alpha \leq 0.50$. As expected, the uncertainties of the FCS and VIS dominate the random and systematic error budgets for all the AOD ranges. For $\mathrm{AOD} \leq 0.10$ the scatter reaches 0.12 and the systematic error is -0.02 , while for $\mathrm{AOD} \geq 0.20$ we obtain a scatter of 0.17 , and a bias of 0.03 . When considering all the AOD range and all the input parameter errors, the overall uncertainty is expected to be less than 0.15 (SD), with a positive bias of 0.03 .

\section{Validation of ANN AOD estimates}

The ANN AOD estimates have been validated with coincident AERONET CIMEL photometers of Level 2.0 AOD (cloud screened and quality ensured) from 2004 to 2009, and with a long-term AOD at $769.9 \mathrm{~nm}$ data series retrieved by Barreto et al. (2014) from a solar spectrometer Mark-I for the period 1975-2012. 
Table 2. Statistics of the difference between non-perturbed and perturbed ANN AOD estimates $(\mathrm{AOD}-(\mathrm{AOD} \pm \delta))$ : Pearson correlation coefficient $(R)$ between the differences and ANN AOD values, standard deviation (SD) and median of the difference time series (systematic bias). "All" represents the error estimation considering the uncertainties of all parameters together (VIS $\pm 25 \%, \mathrm{FCS} \pm 5 \%$ and $\mathrm{RH} \pm 2 \%$ ).

\begin{tabular}{lcrrr}
\hline $\begin{array}{l}\text { AOD } \\
\text { ranges }\end{array}$ & Input & $R$ & SD & $\begin{array}{r}\text { Systematic } \\
\text { bias }\end{array}$ \\
\hline & RH & 0.08 & 0.02 & -0.01 \\
$\leq 0.10$ & FCS & 0.06 & 0.09 & -0.01 \\
$(102$ days $)$ & VIS & 0.05 & 0.04 & -0.01 \\
& All & 0.01 & 0.12 & -0.02 \\
\hline \multirow{3}{*}{$\begin{array}{lrrr}(15 \text { days }) \\
\end{array}$} & RH & -0.26 & 0.05 & 0.01 \\
& FCS & 0.03 & 0.16 & -0.04 \\
All AOD range & VIS & -0.21 & 0.07 & 0.01 \\
& All & -0.01 & 0.17 & 0.03 \\
\hline
\end{tabular}

CIMEL photometers retrieve AOD measurements at different wavelengths between $340-1640 \mathrm{~nm}$ from direct Sun observations under cloud-free conditions, with an expected uncertainty of 0.01 at $500 \mathrm{~nm}$ for field instruments (Eck et al., 1999). The validation procedure of Mark-I AOD time series was performed by Barreto et al. (2014), showing a rootmean-square error of $0.022(R=0.94)$ and $0.034(R=0.92)$ in comparison with the PFR reference and AERONET master instruments, respectively. In order to compare the MarkI AOD values at $769.9 \mathrm{~nm}$ and the ANN AOD estimates at $500 \mathrm{~nm}$, we have extrapolated the ANN AOD values from 500 to $769.9 \mathrm{~nm}$ by using the Ångström law (Ångström, 1929) and the $\alpha$ data retrieved from PFR observations. For Mark-I we have used the AOD records since 1984 when the observations start to be seamlessly performed.

The straightforward comparisons between AOD observations and estimates show a good agreement for the daily values with $\sim 94 \%(R=0.97)$ of the variance in agreement between AERONET AOD and ANN AOD, and $85 \%$ $(R=0.93)$ between Mark-I AOD and ANN AOD values (Fig. 5a and b). When considering monthly values the agreement increases, achieving a correlation of 96 and $98 \%$ with Mark-I/ANN and AERONET/ANN, respectively. Although the comparison with the Mark-I AOD records shows a poorer agreement, both inter-comparisons behave similarly. We observe that the ANN AOD estimates have been shown to be dependent on the AOD range (see Table 3), confirming the results obtained in the theoretical error estimation (Table 2). For low AOD, the ANN AOD values tend to overestimate compared with the observed AOD values (median bias of $\sim 0.01-0.02$ ), but the contrary behaviour is observed for high AOD (underestimation by $0.01-0.03$ ). However, the overall ANN AOD/ Mark-I AOD scatter (0.06) duplicates
Table 3. Statistics for the difference between AOD observations and ANN AOD estimates for different AOD ranges. The series of differences between Mark-I AOD and ANN AOD is at $769.9 \mathrm{~nm}$ in the period 1984-2009 and between AERONET AOD and ANN AOD at $500 \mathrm{~nm}$ in the period 2004-2009. $N$ is the number of data and $R$ is Pearson correlation coefficient. The bold values represent the $R$, random bias and systematic bias considering all AOD range for AERONET and Mark-I, respectively.

\begin{tabular}{lcrrrr}
\hline $\begin{array}{l}\text { AOD } \\
\text { ranges }\end{array}$ & Data & $N$ & $R$ & $\begin{array}{r}\text { Random } \\
\text { bias }\end{array}$ & $\begin{array}{r}\text { Systematic } \\
\text { bias }\end{array}$ \\
\hline$\leq 0.10$ & AERONET & 113 & 0.73 & 0.02 & -0.01 \\
& Mark-I & 691 & 0.62 & 0.04 & -0.02 \\
\hline$\geq 0.20$ & AERONET & 11 & 0.91 & 0.05 & 0.01 \\
& Mark-I & 187 & 0.75 & 0.09 & 0.03 \\
\hline All AOD & AERONET & 154 & $\mathbf{0 . 9 7}$ & $\mathbf{0 . 0 3}$ & $\mathbf{- 0 . 0 1}$ \\
range & Mark-I & 1076 & $\mathbf{0 . 9 3}$ & $\mathbf{0 . 0 6}$ & $\mathbf{- 0 . 0 1}$ \\
\hline
\end{tabular}
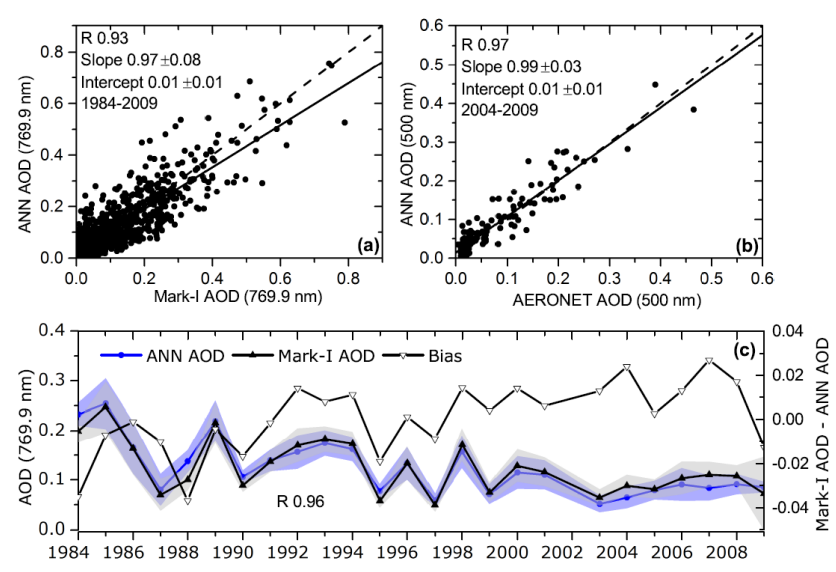

Figure 5. Scatterplot of ANN AOD estimates vs. (a) daily MarkI AOD at $769.9 \mathrm{~nm}$ for all the cloud-free days (oktas=0) and (b) daily AERONET AOD at 500 nm for the periods 1984-2009 and 2004-2009, respectively. The black solid lines are the leastsquare fits and the dotted lines are the diagonals. The least-square fit parameters are shown in the legend (Pearson correlation coefficient, $R$, slope and intercept). (c) Time series of monthly medians of Mark-I AOD and ANN AOD estimates in July (on the left axis) and time series of the differences between these AOD values (on the right axis). Shadings show the range of \pm 1 SEM (standard error of the monthly median).

that observed for the ANN AOD/AERONET AOD comparison (0.03). This agreement is within the AOD uncertainty of Mark-I (Barreto et al., 2014) and within our error estimation (Table 2). Notice that the experimental scatter is significantly smaller than the theoretical one, suggesting that our assumed uncertainties could be very conservative. Therefore, in summary, we consider that the ANN AOD values capture well the day-to-day AOD variability and successfully identify Saharan mineral dust events at IZO. 
The long-term Mark-I AOD time series also allows us to analyse the temporal consistency of the ANN AOD estimations by examining possible drifts and discontinuities in the monthly time series of the differences between ANN AOD and Mark-I AOD for July, August and September. A drift is defined as the linear trend of monthly median bias (measurements-estimations), while the change points (changes in the median of the bias time series) are analysed by using a robust rank order change-point test (Lanzante, 1996). The Lanzante's procedure is an iterative method that applies a (single) change-point test, based on summing the ranks of the values from the beginning to each point in the series, and followed by an adjustment step (the median computed for the segments enclosed by the identified change points is used to adjust the series). In the subsequent iteration the change-point test is applied to the adjusted series and the iterative process finishes when the significance of each new change point is less than an a priori specified level.

By applying this change-point test we identify 1997 as the change point in the monthly median bias time series (see Fig. 5c), caused by the horizontal visibility records. Although this discontinuity is significant at $99 \%$ confidence level, the difference of median bias is rather small $(-0.013 \pm 0.001$ for the 1984-1997 period and $+0.006 \pm 0.003$ for the 1998 2009 period) and within the ANN AOD and Mark-I AOD expected uncertainties. Furthermore, we observe that there are no significant drifts in the bias time series either before or after this systematic change point at $99 \%$ of confidence level. For the other months, August and September, the monthly median bias time series have shown neither significant systematic change points nor temporal drifts. These findings indicate that the ANN AOD estimates are consistent over time and, thus, valid to reconstruct the AOD time series at IZO.

\section{Comparison of long-term ANN AOD with meteorological records}

We have analysed the long-term variability of ANN AOD time series by comparing with long-term meteorological records identifying Saharan dust events at IZO. On the one hand, we have compared the number of days in which estimated ANN AOD values fall within different AOD intervals with the number of days in which the meteorological observers reported presence of dust in suspension (05-06 SYNOP codes, WMO, 1998) at IZO during the dust season (July-September) since 1941 (see Fig. 6a and b). On the other hand, locally at the observatory, when haze or dust in suspension is reported by the observers, the wind normally blows from the second sector $\left(90-180^{\circ}\right)$ (Fig. 6c). Therefore, we have analysed the relation between the monthly AOD medians in July (month with the maximum frequency of Saharan dust events at IZO in the study period) and the monthly percentage of time the wind is blowing from each of the four quadrants for the period 1941-2009. Both analyses provide consistent results. On the one hand, we found that the number of days with 05-06 Synop codes time series agrees with the number of days with ANN AOD $\geq 0.20$ time series $(R=0.89)$. On the other hand, a high correlation $(R=0.86)$ between the ANN AOD monthly medians and the percentage of time the wind blows in the second quadrant is observed, whilst no correlation at all is found in the other three quadrants ( $R$ of $0.24,0.16$ and 0.14 , for the first, third and fourth quadrants, respectively) (see Fig. 6c and d). These results show that the reconstructed ANN AOD series correlates well with other series of independent atmospheric parameters, confirming its consistency in this long period (1941-2009), and probing its capability for tracking interannual variations of dust-laden Saharan air mass outbreaks. The ANN AOD series is suitable to be used in climate analysis.

\section{Summary and conclusions}

This paper presents, for the first time, the AOD time series of Saharan mineral dust outbreaks over the subtropical North Atlantic between 1941 and 2013. This has been done at the Izaña Atmospheric Observatory, frequently affected by the Saharan Air layer during the summer months, and by combining AOD estimates from artificial neural networks between 1941 and 2001, and AOD measurements during the period 2003-2013.

The ANN method has proved to be a very useful tool for the reconstruction of daily AOD values at $500 \mathrm{~nm}$ from meteorological input data, such as the horizontal visibility, fraction of clear sky, and relative humidity, recorded at IZO. ANN AOD estimates adequately capture the day-today AOD variations and the long-term trends when compared to coincident AOD measurements from Mark-I solar spectrometer (1984-2009) and AERONET (2004-2009). The results show a good agreement for the daily values, with Pearson coefficients of 0.97 (AERONET/ANN) and 0.93 (MarkI/ANN). At the longest timescale (1941-2009), we found a good agreement between ANN AOD monthly medians and the percentage of time the wind blows from the Sahara desert (SE) $(R=0.86)$, and also a good correlation between the number of days with $A O D \geq 0.20$ and the number of days in which synoptical observations reported mineral dust events ( $R=0.89$ ). These results show the reliability of the reconstructed ANN AOD series, confirming its consistency in this long period (1941-2009), and capability for tracking interannual variations of dust-laden Saharan air mass outbreaks.

Finally, this paper also highlights the potential of ANN to estimate AOD values and probe its suitability for long-term AOD series reconstruction. Thereby, the ANN methodology developed here for AOD series reconstruction might be suitable to be applied in Synoptic stations of North Africa, the Middle East and Asia, in which the reduced visibility is primarily due to the presence of mineral dust, and where recent AOD observations are available for validation. 

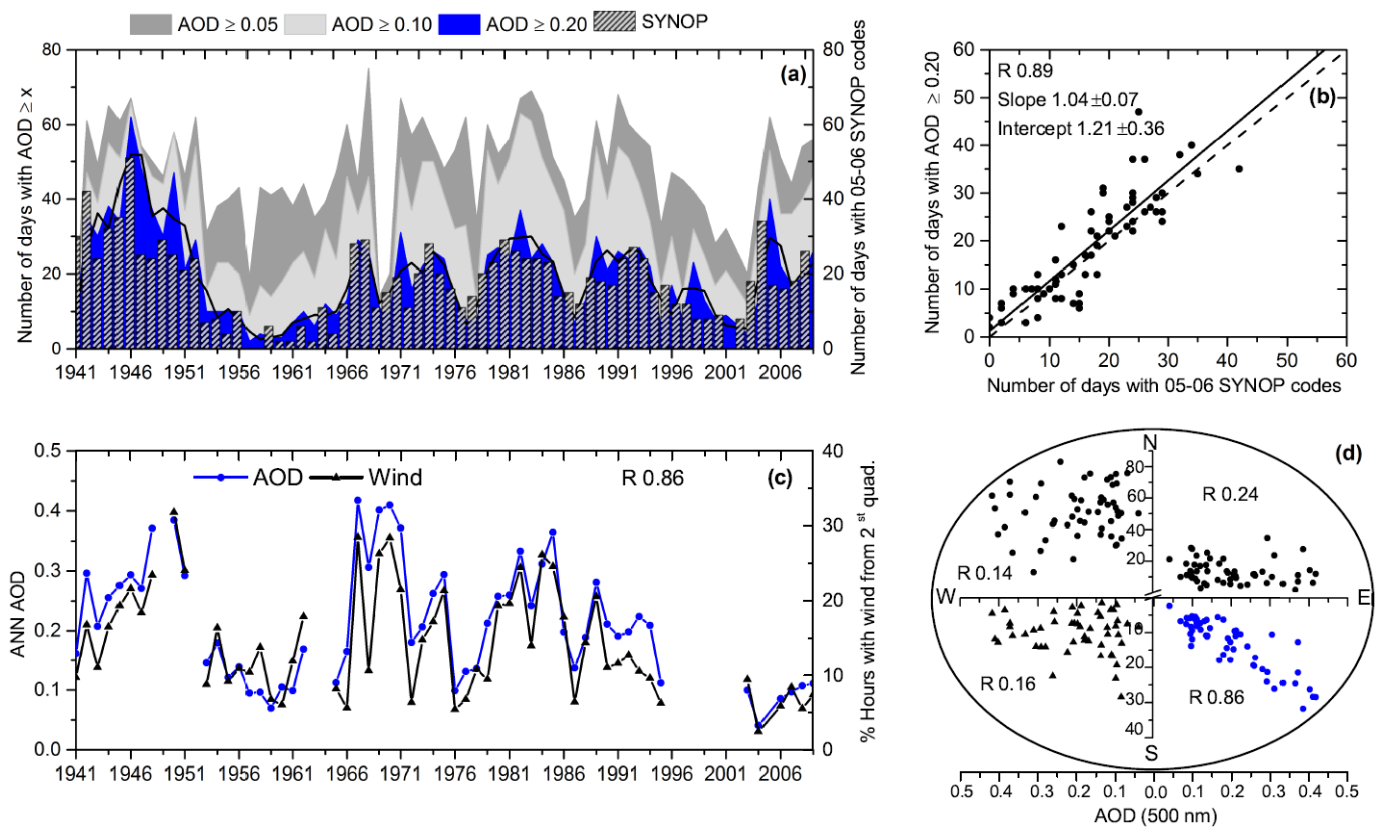

Figure 6. (a) Time series of the number of days grouped into ANN AOD intervals (AOD $\geq 0.05 ; A O D \geq 0.10 ; A O D \geq 0.20$ ) on the left axis, while on the right axis, the bars indicate the number of days with SYNOP data reporting dust in suspension (05-06 SYNOP codes) for the period 1941-2009. The 5-year running mean is shown in black. (b) Scatterplot of number of days with ANN AOD $\geq 0.20$ and number of days with 05-06 SYNOP codes. The least-square fit parameters are shown in the legend. (c) Time series of the ANN AOD monthly medians (blue line) and monthly percentage of time the wind blows from the second quadrant (E-S; $90-180^{\circ}$ ) (black line) at IZO in July in the period 1941-2009. (d) Percentage of time ( $y$ axis) the wind blows from in each one of the four quadrants vs. the ANN AOD monthly medians ( $x$ axis). $R$ indicates the Pearson coefficient.

Acknowledgements. This work was developed under the Specific Agreement of Collaboration between the Meteorological State Agency (AEMET) of Spain and the University of Valladolid regarding radiometry, ozone and atmospheric aerosol programmes conducted at Izaña Atmospheric Observatory (IZO), and for the adaptation and integration of the AEMET CIMEL network following the AERONET-RIMA standards. This study is also part of the activities carried out within the WMO CIMO Testbed for Aerosols and Water Vapor Remote Sensing instruments at Izaña Observatory. The AERONET Cimel sun photometer at Izaña has been calibrated by AERONET-EUROPE Calibration Service, financed by the Aerosol Cloud and TRace gas InfraStructure (ACTRIS) European Research Infrastructure Action (FP7/2007-2013 no. 262254). Financial support from the Spanish Ministry of Economy and Competitiveness (MINECO) and from the "Fondo Europeo de Desarrollo Regional" (FEDER) for project CGL2012-33576 is gratefully acknowledged. We thank the AERONET-GSFC, PHOTONS-LOA, RIMA-UVa, and RIMA-CIAI (AEMET) staff for their scientific and technical support. The authors are grateful to the IZO team and especially all observers who have worked in the past at Izaña Atmospheric Observatory. We also acknowledge our colleague Celia Milford for improving the English language of the paper.

Edited by: O. Torres

\section{References}

Ångström, A. K.: On the atmospheric transmission of sun radiation and on the dust in the air, Geogr. Ann., 12, 130-159, 1929.

Barreto, A., Cuevas, E., Pallé, P., Romero, P. M., Guirado, C., Wehrli, C. J., and Almansa, F.: Recovering long-term aerosol optical depth series (1976-2012) from an astronomical potassiumbased resonance scattering spectrometer, Atmos. Meas. Tech., 7, 4103-4116, doi:10.5194/amt-7-4103-2014, 2014.

Beale, M. H., Hagan, M. T., and Demuth, H. B.: Neural Network Toolbox, User's Guide, The MathWorks Inc., Natick, MA, USA, 2014.

Cazorla, A., Olmo, F. J., and Alados-Arboledas, L.: Using a sky imager for aerosol characterization, Atmos. Environ., 42, 27392745, 2008.

Cerdeña, A., González, A., and Pérez, J. C.: Remote sensing of water cloud parameters using neural networks, J. Atmos. Ocean. Tech., 24, 52-63, doi:10.1175/JTECH1943.1, 2006.

Cuevas, E.: Estudio del Comportamiento del Ozono Troposférico en el Observatorio de Izaña (Tenerife) y su Relación con la Dinámica Atmosférica, Thesis, Univ. Complutense de Madrid, Madrid, Spain, 1996.

Cuevas, E., González, Y., Rodríguez, S., Guerra, J. C., GómezPeláez, A. J., Alonso-Pérez, S., Bustos, J., and Milford, C.: Assessment of atmospheric processes driving ozone variations in the subtropical North Atlantic free troposphere, Atmos. Chem. Phys., 13, 1973-1998, doi:10.5194/acp-13-1973-2013, 2013. 
Cuevas, E., Milford, C., Bustos, J. J., del Campo-Hernández, R., García, O. E., García, R. D., Gómez-Peláez, A. J., Ramos, R., Redondas, A., Reyes, E., Rodríguez, S., Romero-Campos, P. M., Schneider, M., Belmonte, J., Gil-Ojeda, M., Almansa, F., Alonso-Pérez, S., Barreto, A., Guirado-Fuentes, C., LópezSolano, C., Afonso, S., Bayo, C., Berjón, A., Bethencourt, J., Camino, C., Carreño, V., Castro, N. J., Cruz, A. M., Damas, M., De Ory-Ajamil, F., García, M. I., Fernández-de Mesa, C. M. González, Y., Hernández, C., Hernández, Y., Hernández, M.A., Hernández, B., Jover, M., Kühl, S. O., López-Fernández, R., López-Solano, J., Peris, A., Rodríguez-Franco, J. J., Sálamo, C., Sepúlveda, E., and Sierra-Ramos, M.: Izaña Atmospheric Research Center Activity Report 2012-2014, edited by: Cuevas, E. and Milford, C., NIPO: 281-15-004-2, State Meteorological Agency (AEMET), Madrid, Spain, 2015a.

Cuevas, E., Camino, C., Benedetti, A., Basart, S., Terradellas, E., Baldasano, J. M., Morcrette, J. J., Marticorena, B., Goloub, P., Mortier, A., Berjón, A., Hernández, Y., Gil-Ojeda, M., and Schulz, M.: The MACC-II 2007-2008 reanalysis: atmospheric dust evaluation and characterization over northern Africa and the Middle East, Atmos. Chem. Phys., 15, 3991-4024, doi:10.5194/acp-15-3991-2015, 2015b.

De Bruin, H. A. R., Van den Hurk, B. J. J. M., and Welgraven, D.: A series of global radiation at Wageningen for 1928-1992, Int. J. Climatol., 15, 1253-1272, doi:10.1002/joc.3370151106, 1995.

Demuth, H. and Beale, M.: Neural network toolbox for use with MATLAB, Natick, MA, USA, 1993.

Dirección General del Instituto Geográfico y Estadístico: Observatorio Atmosférico de Izaña, Anual del Observatorio Central Meteorológico, Sumplemento al tomo III, 1915.

Dorvlo, A. S., Jervase, J. A., and Al-Lawati, A.: Solar radiation estimation using artificial neural networks, Appl. Energ., 71, 307319, 2002.

Eck, T. F., Holben, B. N., Reid, J. S., Dubovik, O., Smirnov, A., O'Neill, N. T., Slutsker, I., and Kinne, S.: Wavelength dependence of the optical depth of biomass burning, urban, and desert dust aerosols, J. Geophys. Res., 104, 31333-31349, doi:10.1029/1999JD900923, 1999.

Feister, U. and Junk, J.: Reconstruction of daily solar UV irradiation by an artificial neural network (ANN), Remote Sensing of Clouds and the Atmosphere, 6362, 63622-63622, 2006.

Feister, U., Junk, J., Woldt, M., Bais, A., Helbig, A., Janouch, M., Josefsson, W., Kazantzidis, A., Lindfors, A., den Outer, P. N., and Slaper, H.: Long-term solar UV radiation reconstructed by ANN modelling with emphasis on spatial characteristics of input data, Atmos. Chem. Phys., 8, 3107-3118, doi:10.5194/acp8-3107-2008, 2008.

Foresee, F. D. and Hagan, M. T.: Gauss-Newton approximation to Bayesian learning, In Proceedings of the 1997 international joint conference on neural networks, Piscataway: IEEE, 3, 19301935, 1997.

Foyo-Moreno, I., Alados, I., Antón, M., Fernández-Gálvez, J., Cazorla, A., and Alados-Arboledas, L.: Estimating aerosol characteristics from solar irradiance measurements at an urban location in southeastern Spain, J. Geophys. Res.-Atmos., 119, 18451859,2014

García, R. D., Cuevas, E., García, O. E., Cachorro, V. E., Pallé, P., Bustos, J. J., Romero-Campos, P. M., and de Frutos, A. M.: Reconstruction of global solar radiation time series from 1933 to
2013 at the Izaña Atmospheric Observatory, Atmos. Meas. Tech., 7, 3139-3150, doi:10.5194/amt-7-3139-2014, 2014a.

García, R. D., García, O. E., Cuevas, E., Cachorro, V. E., RomeroCampos, P. M., Ramos, R., and de Frutos, A. M.: Solar radiation measurements compared to simulations at the BSRN Izaña station. Mineral dust radiative forcing and efficiency study, J. Geophys. Res., 119, 179-194, doi:10.1002/2013JD020301, 2014 b.

Gilgen, H., Wild, M., and Ohmura, A.: Means and trends of shortwave irradiance at the surface estimated from GEBA, J. Climate, 11, 2042-2061, 1998.

González, A., Pérez, J. C., Herrera, F., Rosa, F., Wetzel, M. A., Borys, R. D., and Lowenthal, D. H.: Stratocumulus properties retrieval method from NOAA-AVHRR data based on the discretization of cloud parameters, Int. J. Remote Sens., 23, 627645, 2002.

González, Y., Schneider, M., Rodríguez, S., Cuevas, E., Dyroff, C., Christner, E., Andrey, J., García, O., and Sepúlveda, E.: Measurements and interpretation of the water vapor $\delta \mathrm{D}$ variability at Izaña North Atlantic free troposphere site, Symposium on Atmospheric Chemistry and Physics at Mountain Sites, 11-15 August 2014, Steamboat Springs, CO, USA, 2014.

Hao, Y. and Wilamowski, B. M.: Levenberg-Marquardt Training. Industrial Electronics Handbook, vol. 5, Intelligent Systems, CRC Press, Boca Raton, FL, USA, 2nd Edition, chapter 12, 12-1 to $12-15,2011$.

Holben, B. N., Tanré, D., Smirnov, A., Eck, T. F., Slutsker, I., Abuhassan, N., Newcomb, W. W., Schafer, J. S., Chatenet, B., Lavenu, F., Kaufman, Y. J., Vande Castle, J., Setzer, A.,Markham, B., Clark, D., Frouin, R., Halthore, R., Karneli, A., O'neill, N. T., Pietras, C., Pinker, C., Voss, K., and Zibordi, G.: An emerging ground-based aerosol climatology: Aerosol Optical Depth from AERONET, J. Geophys. Res.-Atmos., 106, 12067 12097, doi:10.1029/2001JD900014, 2001.

Jain, A. K., Mao, J., and Mohiuddin, K. M.: Artificial neural networks: A tutorial, Computer, 3, 31-44, 1996.

Junk, J., Feister, U., and Helbig, A.: Reconstruction of daily solar UV irradiation from 1893 to 2002 in Potsdam, Germany, Int. J. Biometeorol., 51, 505-512, 2007.

Kaufman, Y. J., Gitelson, A., Karnieli, A., Ganor, E., and Fraser, R. S.: Size distribution and phase function of aerosol particles retrieved from sky brightness measurements, J. Geophy. Res.Atmos., 99, 10331-10356, 1994.

Kaufman, Y. J., Tanré, D., and Boucher, O.: A satellite view of aerosols in the climate system, Nature, 419, 215-223, 2002.

Kim, D., Chin, M., Yu, H., Eck, T. F., Sinyuk, A., Smirnov, A., and Holben, B. N.: Dust optical properties over North Africa and Arabian Peninsula derived from the AERONET dataset, Atmos. Chem. Phys., 11, 10733-10741, doi:10.5194/acp-1110733-2011, 2011.

Kudo, R., Uchiyama, A., Yamazaki, A., Sakami, T., and Ijima, O.: Decadal changes in aerosol optical thickness and single scattering albedo estimated from ground-based broadband radiometers: A case study in Japan, J. Geophys. Res.-Atmos. (1984-2012), 116, D03207, doi:10.1029/2010JD014911 2011.

Lachat, D. and Wehrli, C. : Dimming and brightening trends in direct solar irradiance from 1909 to 2010 over Davos, Switzerland: Proportions of aerosol and gaseous transmission, J. Geophys Res.-Atmos., 118, 3285-3291, doi:10.1002/jgrd.50344, 2013 
Lanzante, J. R.: Resistant, robust and nonparametric techniques for the analysis of climate data: Theory and examples including applications to historical radiosonde station data, Int. J. Climatol., 16, 1197-1226, 1996.

Linares-Rodríguez, A., Ruiz-Arias, J. A., Pozo-Vázquez, D., and Tovar-Pescador, J.: Generation of synthetic daily global solar radiation data based on ERA-Interim reanalysis and artificial neural networks, Energy, 36, 5356-5365, 2011.

Linares-Rodríguez, A., Ruiz-Arias, J. A., Pozo-Vázquez, D., and Tovar-Pescador, J.: An artificial neural network ensemble model for estimating global solar radiation from Meteosat satellite images, Energy, 61, 636-645, 2013.

López, G., Batlles, F. J., and Tovar-Pescador, J.: Selection of input parameters to model direct solar irradiance by using artificial neural networks, Energy, 30, 1675-1684, 2005.

Mohandes, M., Rehman, S., and Halawani, T. O.: Estimation of global solar radiation using artificial neural networks, Renew. Energ., 14, 179-184, doi:10.1016/S0960-1481(98)00065-2, 1998.

Ohmura, A.: Observed long-term variations of solar irradiances at the Earth's surface, Space Sci. Rev., 125, 111-128, 2006.

Ohmura, A. and Lang, H.: Secular variation of global radiation over Europe, in: Current Problems in Atmospheric Radiation, edited by: Lenoble, J. and Geleyn, J. F., 298-301, 1989.

Ohvril, H., Teral, H., Neiman, L., Kannel, M., Uustare, M., Tee, M., Russak, V., Okulov, O., Joeveer, A., Kallis, A., Ohvril, T., Terez, E. I., Terez, G. A., Gushchin, G. K., Abakumova, G. M., Gorbarenko, E. V., Tsvetkov, A. V., and Laulainen, N.: Global dimming and brightening versus atmospheric column transparency, Europe, 1906-2007, J. Geophys. Res.-Atmos., 114, D00D12, doi:10.1029/2008JD010644, 2009.

Özkan, C. and Erbek, F. S.: The Comparison of Activation Functions for Multispectral Landsat TM Image Classification, Photogramm. Eng. Rem. S., 69, 1225-1234, 2013.

Pallé, E. and Butler, C. J.: Sunshine records from Ireland: Cloud factors and possible links to solar activity and cosmic rays, Int. J. Climatol., 21, 709-729, doi:10.1002/joc.657, 2001.

Paoli, C., Voyant, C., Muselli, M., and Nivet, M. L.: Solar radiation forecasting using ad-hoc time series preprocessing and neural networks, In emerging Intelligent Computing technology and Applications, Springer Berlin Heidelberg, Germany, 898-907, 2009.

Prospero, J., Ginoux, P., Torres, O., and Nicholson, S.: Environmental characterization of global sources of atmospheric soil dust derived from the NIMBUS7 (TOMS) absorbing aerosol product, Review Geophysical, 40, 1002, doi:10.1029/2000RG000095, 2002.

Retalis, A., Hadjimitsis, D. G., Michaelides, S., Tymvios, F., Chrysoulakis, N., Clayton, C. R. I., and Themistocleous, K.: Comparison of aerosol optical thickness with in situ visibility data over Cyprus, Nat. Hazards Earth Syst. Sci., 10, 421-428, doi:10.5194/nhess-10-421-2010, 2010.
Rodríguez, S., Alastuey, A., Alonso-Pérez, S., Querol, X., Cuevas, E., Abreu-Afonso, J., Viana, M., Pérez, N., Pandolfi, M., and de la Rosa, J.: Transport of desert dust mixed with North African industrial pollutants in the subtropical Saharan Air Layer, Atmos. Chem. Phys., 11, 6663-6685, doi:10.5194/acp-11-66632011, 2011.

Rodríguez, S., Cuevas, E., Prospero, J. M., Alastuey, A., Querol, X., López-Solano, J., García, M. I., and Alonso-Pérez, S.: Modulation of Saharan dust export by the North African dipole, Atmos. Chem. Phys., 15, 7471-7486, doi:10.5194/acp-15-74712015, 2015.

Sanchez-Lorenzo, A., Brunetti, M., Calbo, J., and Martin-Vide, J.: Recent spatial and temporal variability and trends of sunshine duration over the Iberian Peninsula from a homogenized data set, J. Geophys. Res., 112, D20115, doi:10.1029/2007JD008677, 2007.

Shaw, G. E.: Aerosols at Mauna Loa, Optical properties, J. Atmos. Sci., 36, 862-869, 1979.

Stanhill, G. and Cohen, S.: Global dimming: a review of the evidence for a widespread and significant reduction in global radiation, Agr. For. Meteorol., 107, 255-278, doi:10.1016/S01681923(00)00241-0, 2001.

Thies, A.: Instruction Manual Hygro-thermo transmitter compact, Adolf THIES GmbH \& Co. KG, Göttingen, Germany, 2011.

Wehrli, C.: Calibrations of filter radiometers for determination of atmospheric optical depth, Metrologia, 37, 419-422, 2000.

Wild, M., Gilgen, H., Roesch, A., Ohmura, A., Long, C. N., Dutton, E. G., Forgan, B., Kallis, A., Russak, V., and Tsvetkov, A.:From dimming to brightening: Decadal changes in surface solar radiation, Science, 308, 847-850, doi:10.1126/science.1103215, 2005.

Wild, M., Grieser, J., and Schär, C.: Combined surface solar brightening and increasing greenhouse effect support recent intensification of the global land-based hydrological cycle, Geophys. Res. Lett., 35, L17706, doi:10.1029/2008GL034842, 2008.

Wild, M.: Global dimming and brightening: A review, J. Geophys. Res., 114, D00D16, doi:10.1029/2008JD011470, 2009.

World Meteorological Organization (WMO), Guide to meteorological instruments and methods of observation. 6th ed. WMO no. 8 . Secretariat of the World Meteorol. Organ., Geneva, Switzerland, 1996.

World Meteorological Organization (WMO), Manual on Codes, Regional Codes and National Coding Practices, Volumen II, Secretariat of the World Meteorological Organization, WMO 306, Geneva, Switzerland, 1998.

Zhang, G., Patuwo, B. E., and Hu, M. Y.: Forecasting with artificial neural networks: The state of the art, Int. J. Forecasting, 14, 35$62,1998$. 